\title{
Dietary patterns in India and their association with obesity and central obesity
}

\author{
Ambika Satija ${ }^{1, *}$, Frank B Hu ${ }^{1}$, Liza Bowen ${ }^{2}$, Ankalmadugu V Bharathi ${ }^{3}$, Mario Vaz $^{4}$, \\ Dorairaj Prabhakaran ${ }^{5}, \mathrm{~K}$ Srinath Reddy ${ }^{6}$, Yoav Ben-Shlomo ${ }^{7}$, George Davey Smith7, \\ Sanjay Kinra ${ }^{2}$ and Shah Ebrahim ${ }^{2,8}$ \\ 'Departments of Nutrition \& Epidemiology, Harvard School of Public Health, 677 Huntington Avenue, Boston, \\ MA 02115 , USA: ${ }^{2}$ Department of Non-communicable Disease Epidemiology, London School of Hygiene and \\ Tropical Medicine, London, UK: ${ }^{3}$ Mount Carmel College, Indira Gandhi National Open University, Bangalore, India: \\ ${ }^{4}$ Division of Nutrition, St John's Research Institute, Bangalore, India: ${ }^{5}$ Centre for Chronic Disease Control, New Delhi, \\ India: ${ }^{6}$ Public Health Foundation of India, ISID Campus, New Delhi, India: ${ }^{7}$ School of Social and Community \\ Medicine, University of Bristol, Bristol, UK: ${ }^{8}$ South Asia Network For Chronic Disease, Public Health Foundation of \\ India, New Delhi, India
}

Submitted 11 January 2014: Final revision received 18 December 2014: Accepted 6 January 2015: First published online 20 February 2015

\begin{abstract}
Objective: Obesity is a growing problem in India, the dietary determinants of which have been studied using an 'individual food/nutrient' approach. Examining dietary patterns may provide more coherent findings, but few studies in developing countries have adopted this approach. The present study aimed to identify dietary patterns in an Indian population and assess their relationship with anthropometric risk factors.

Design: FFQ data from the cross-sectional sib-pair Indian Migration Study (IMS; $n$ 7067) were used to identify dietary patterns using principal component analysis. Mixed-effects logistic regression was used to examine associations with obesity and central obesity.

Setting: The IMS was conducted at four factory locations across India: Lucknow, Nagpur, Hyderabad and Bangalore.

Subjects: The participants were rural-to-urban migrant and urban non-migrant factory workers, their rural and urban resident siblings, and their co-resident spouses.

Results: Three dietary patterns were identified: 'cereals-savoury foods' (cooked grains, rice/rice-based dishes, snacks, condiments, soups, nuts), 'fruit-vegsweets-snacks' (Western cereals, vegetables, fruit, fruit juices, cooked milk products, snacks, sugars, sweets) and 'animal-food' (red meat, poultry, fish/ seafood, eggs). In adjusted analysis, positive graded associations were found between the 'animal-food' pattern and both anthropometric risk factors. Moderate intake of the 'cereals-savoury foods' pattern was associated with reduced odds of obesity and central obesity.

Conclusions: Distinct dietary patterns were identified in a large Indian sample, which were different from those identified in previous literature. A clear 'plant food-based/animal food-based pattern' dichotomy emerged, with the latter being associated with higher odds of anthropometric risk factors. Longitudinal studies are needed to further clarify this relationship in India.
\end{abstract}

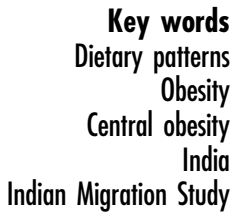

Globally, the past two to three decades have seen a rise in the prevalence of obesity, a risk factor for chronic diseases such as CVD and diabetes, to which dietary factors have been linked $^{(1)}$. Traditionally, nutritional epidemiology has evaluated individual food/nutrient consumption as it relates to disease profiles. A new trend, with established reproducibility and validity, has been to assess composite dietary patterns ${ }^{(2,3)}$. The rationale is that since foods are eaten together, their combined consumption might have a different impact on health than their isolated intake. This also circumvents certain methodological challenges of individual food/nutrient analysis, such as confounding by other 
foods/nutrients and collinearity ${ }^{(4)}$. Additionally, assessing the impact of composite diets on disease risk might be more relevant for making dietary recommendations ${ }^{(4-7)}$.

One of the methods used under this approach is an a posteriori one - using data reduction techniques to elicit predominant dietary patterns from existing data, using which two dietary patterns have been most commonly found: the 'Western' diet (high intakes of meat, high-fat dairy, refined grains and fast foods) and the 'prudent' diet (high intakes of fruits, vegetables, fish, whole grains, legumes and low-fat dairy) $)^{(5,6,8,9)}$. In several longitudinal studies, patterns characterized by high intakes of fruit, vegetables, reduced-fat dairy and fibre have been associated with reduced weight gain relative to those characterized by high intakes of meat, potatoes and refined grains $^{(4,10-12)}$.

Such analysis has essentially been done either in Western countries ${ }^{(13)}$ or in large global samples using highly simplified food group frequency questionnaires ${ }^{(14)}$, and the generalizability of the conclusions of these studies to other countries is questionable. This is particularly true for India, where there are unique and diverse food cultures, and which is also in the middle of a "nutrition transition, (15). Therefore the objective of the present study was to ascertain predominant dietary patterns among Indians and assess their associations with obesity and central obesity.

\section{Methods}

\section{Study design}

Data from the Indian Migration Study (IMS) were used, details of which have been described previously ${ }^{(16-18)}$. The IMS is a cross-sectional sib-pair study, carried out in factory settings in four cities from northern, central and southern India (Lucknow, Nagpur, Hyderabad and Bangalore), consisting of 7067 participants (4123 men and 2944 women). Rural-to-urban migrant factory workers, and a $25 \%$ random sample of urban non-migrants, along with their co-resident spouses, were asked to participate. Each migrant participant was asked to identify a sibling residing in a rural area, preferably of the same gender and similar age, who was then invited to participate. A substantial proportion of the rural sample so generated came from the four states in which the factories were based. The urban participants were also asked to identify a nonmigrant, urban-dwelling sibling for inclusion in the study. Fieldwork took place between March 2005 and December 2007. The study was conducted according to the guidelines laid down in the Declaration of Helsinki and all procedures involving human subjects were approved by the All India Institute of Medical Sciences Ethics Committee (reference number A-60/4/8/2004). Informed consent was obtained from all participants; after translation into local languages, information sheets were signed, or if the person was illiterate, a thumb print was used.

\section{Antbropometric measurement}

A digital weighing machine with $100 \mathrm{~g}$ accuracy (model PS16; Beurer, Ulm, Germany) was used to weigh participants while in light indoor clothing. For measuring height, the Frankfort plane was used with a portable plastic stadiometer with a base plate, with $1 \mathrm{~mm}$ accuracy (Leicester height measure; Chasmors, London, UK). Two measures of waist circumference were taken at the narrowest part of the abdomen between the ribs and the iliac crest, as seen from the anterior aspect, on bare skin, with a non-stretchable metallic tape with a blanket lead-in (Chasmors). Obesity was defined as having a BMI (weight/ height $^{2}$ ) $\geq 25.0 \mathrm{~kg} / \mathrm{m}^{2(19)}$ and central obesity as having a waist circumference $\geq 94.0 \mathrm{~cm}$ for men and $\geq 80.0 \mathrm{~cm}$ for women ${ }^{(20)}$.

\section{Dietary assessment}

Frequency of consumption of various food items was measured using an interviewer-administered semiquantitative $\mathrm{FFQ}^{(18,21,22)}$, which assessed frequency of intake (number of portions consumed on a daily, weekly, monthly, yearly/never basis) of 184 commonly consumed food items in India. For reliability assessment, sub-samples of participants from the IMS were asked to complete the questionnaire one to two months ( $n$ 185) and twelve months ( $n$ 305) after original data collection. Kappa coefficients ranging from 0.26 to 0.71 were obtained $^{(16)}$, which are similar to values obtained in other studies ${ }^{(23,24)}$. Another 530 participants (urban participants sampled from the IMS and rural participants recruited from rural areas neighbouring IMS factory sites) were administered a reference method of three $24 \mathrm{~h}$ recalls to validate the FFQ. Details of this validation sub-study have been published previously $^{(22)}$. In brief, most food groups yielded acceptable validities, with Spearman correlation coefficients ranging from 0.25 for egg to 0.72 for cereals. Indian food composition tables (and where nutrient composition was unavailable from the Indian tables, the US Department of Agriculture nutrient database or McCance and Widdowson's The Composition of Foods) were used to estimate the nutrient content of both whole foods as well as cooked Indian foods (for which weighted recipes were obtained from participants from rural and urban areas of all four regions). Intake frequency data from the FFQ were then linked to this nutrient composition database to derive nutrient and total energy intakes per day. When examining validity in terms of nutrients, de-attenuated correlation coefficients between the two methods ranged from 0.57 for fat intake to 0.87 for protein intake.

For the present study, 182 food items (two food items, bhagar and kesari bhath, from the grains and sweets categories, respectively, were removed due to a high number of missing values) were classified into thirty food groups on the basis of nutrient and culinary similarities (some individual foods were retained as separate food groups; see online supplementary material, Supplemental Table 1) for identification of dietary patterns. 


\section{Socio-economic, demographic and lifestyle variables}

An interviewer-administered questionnaire was used to gather information on socio-economic and demographic indicators. The Standard of Living Index (SLI) was calculated by applying standard weights to subsets of questions from a household-level asset-based scale devised for Indian surveys and rescaling them to the full score, which was categorized into tertiles ${ }^{(16)}$. The questionnaire also asked participants about lifestyle variables such as current tobacco use (smoked/chewed on a daily basis in the previous 6 months) and regular alcohol consumption (on $\geq 10 \mathrm{~d}$ /month in the previous 6 months). A physical activity questionnaire (IMS-PAQ) developed for the IMS, validated for use in Indian populations, ascertained participants' habitual daily activity over the previous month in MET $\times \mathrm{h} / \mathrm{d}^{(25)}$ (where MET is metabolic equivalent of task).

\section{Statistical analysis}

The thirty food groups were used to identify dietary patterns using principal component analysis. Principal components so generated were rotated by an orthogonal transformation (varimax) to increase interpretability. An eigenvalue cut-off $>1$, scree plot and component interpretability were used to decide the number of components to retain, which were labelled on the basis of meaningful interpretation of factor loadings and previous literature. Component scores were then generated for each retained component for use in the final analysis, as follows: the intake of each food group was weighted by its appropriate factor loading on a principal component and all of the weighted intakes were then summed to obtain a component score for that principal component, for each individual. For further analysis, known diabetics ( $n$ 486, 6.9\%) were excluded as diagnosis with diabetes may change dietary habits. Thus the final analysis was based on 6581 participants aged 18 years and above. Mixed-effects logistic regression models were used to assess the association of these dietary patterns with obesity and central obesity, separately for men and women, adjusting for age, SLI, education, factory location, migration, tobacco use, alcohol consumption, energy intake and physical activity. All analyses were conducted using the statistical software package STATA 12. $P$ values $<0.05$ were considered statistically significant.

\section{Results}

\section{Dietary patterns}

Table 1 shows the factor loadings of food groups on the three major dietary patterns identified. There were seven factors which met the eigenvalue $>1$ criterion; of these only the first three were considered for further analysis on

Table 1 Factor loadings for the three main dietary patterns identified using principal component analysis of FFQ data from the Indian Migration Study, 2006‡

\begin{tabular}{|c|c|c|c|}
\hline Food group & 'Cereals-savoury foods' pattern & 'Fruit-veg-sweets-snacks' pattern & 'Animal-food' pattern \\
\hline Whole grains§ & - & - & - \\
\hline Whole/refined grains (mixed dishes)§ & 0.17 & - & - \\
\hline Plain rice§ & 0.32 & - & - \\
\hline Rice (mixed dishes)§ & 0.33 & - & - \\
\hline Western cereals§ & - & 0.24 & - \\
\hline Pulses and legumes§ & - & - & - \\
\hline Green leafy vegetables§ & - & - & - \\
\hline Potato§ & -0.41 & - & - \\
\hline Other vegetables§ & -0.31 & 0.21 & - \\
\hline Fruits & - & 0.49 & - \\
\hline Fruit juice & - & 0.27 & - \\
\hline Milk and milk products & - & - & - \\
\hline Milk and milk products (mixed dishes)§ & $-0 \cdot 16$ & 0.22 & - \\
\hline Red meats§ & - & - & 0.49 \\
\hline Poultry§ & - & - & 0.47 \\
\hline Fish and other seafood§ & - & - & 0.48 \\
\hline Eggs§ & - & - & 0.33 \\
\hline Other non-vegetarian§ & - & - & - \\
\hline Mutton or chicken§ & - & - & 0.39 \\
\hline Fats & - & - & - \\
\hline Sugars & - & 0.26 & - \\
\hline Alcohol & - & - & - \\
\hline Tea & - & - & - \\
\hline Coffee & 0.34 & $-0 \cdot 18$ & - \\
\hline Sugar-sweetened beverages & - & - & - \\
\hline Nuts & $0 \cdot 18$ & - & - \\
\hline Snacks§ & $0 \cdot 18$ & 0.41 & - \\
\hline Sweets and deserts§ & - & 0.41 & - \\
\hline Condiments, pickles, chutneys§ & 0.36 & 0.24 & - \\
\hline Soups§ & 0.31 & - & - \\
\hline
\end{tabular}

$\ddagger$ Absolute values $<0.15$ excluded from the table for simplicity.

$\S$ Food group intake based on cooked quantities of constituent food items. 
the basis of the scree plot and their interpretability; in addition, no significant associations were found between the last four patterns and anthropometric indicators (data not shown).

Together, the first three patterns explained $28.6 \%$ of the total variance. Component 1 loaded positively on whole/refined grains (mixed dishes), plain rice, rice-based dishes, coffee, nuts, snacks, condiments and soups, and negatively on potato, other vegetables and cooked milk products. Due to its heavy loading on three cereal groups, and on savoury foods such as nuts, snacks and condiments, this component was termed the 'cereals-savoury foods' dietary pattern. Component 2 loaded positively on Western cereals, other vegetables, fruit, fruit juices, milk products (mixed dishes), snacks, condiments, sugars and sweets, and negatively on coffee. As this component loaded most heavily on fruits, snacks and sweets, and was the only component of the three to load on vegetables, it was termed the 'fruit-veg-sweets-snacks' dietary pattern. Component 3 loaded heavily on all animal-food groups (red meat, poultry, fish/seafood, eggs and other foods made with mutton/chicken) except other non-vegetarian food, the dairy-based categories and fats; hence it was termed the 'animal-food' dietary pattern.

Table 2 shows sample characteristics for the entire sample and according to dietary pattern quintiles. The sample was $41.7 \%$ female with a mean age of 40.8 years, with more than $80 \%$ being in the high SLI category, less than $10 \%$ being illiterate and $22 \%$ and $16 \%$ being current smokers and drinkers, respectively. The highest quintiles of intake of the 'cereals-savoury foods' and 'animal-food' patterns had participants who were on average older and less active, and the highest quintiles of intake of the 'cereals-savoury foods' and the 'fruitveg-sweets-snacks' patterns had higher proportions of literate, high SLI and urban groups, relative to those in the lowest quintiles of intake of these patterns. The 'cereals-savoury foods' and 'animal-food' patterns were consumed by greater proportions in the southern Indian states, while the opposite was true for the 'fruitveg-sweets-snacks' pattern. Other sociodemographic and lifestyle variables also varied with differing quintiles of intake of the three patterns.

Table 2 also shows mean daily intakes of total energy, other nutrients and food groups according to dietary pattern quintiles. Participants with higher scores on all three patterns had higher intakes of total energy, fibre and folate, and higher percentage of energy from fats, relative to participants with lower scores. Participants with higher intake of the 'cereals-savoury foods' pattern had higher percentage of total energy from carbohydrates, and those with higher intake of the 'animal-food' pattern had higher percentage of energy from protein. Food group consumption followed trends as expected from the factor loadings obtained through principal component analysis.

\section{Association of dietary patterns with antbropometric variables}

Participants in the highest quintile of intake of the 'cerealssavoury foods' pattern tended to have, on average, higher BMI values and lower waist circumference values. Participants in the highest quintile of intake of the 'fruit-vegsweets-snacks' pattern had marginally lower values for both anthropometric variables, while the opposite was true for the 'animal-food' pattern (Table 2).

Results of the age-adjusted and fully adjusted regression analyses are shown in Table 3 (men) and Table 4 (women). Age-adjusted models of the 'animal-food' pattern demonstrated a positive, graded association across quintiles with obesity (men: OR for Q5 $v$. Q1 $=1.57 ; 95 \%$ CI 1.19, 2.07; $P$ value for trend $<0 \cdot 001$; women: OR for Q5 $v . \mathrm{Q} 1=2 \cdot 76 ; 95 \%$ CI 1.97, 3.87; $P$ value for trend $<0 \cdot 001$ ) and similar findings were observed for central obesity. Further adjustment for a wide range of potential confounders only modestly altered these findings (Figs 1 and 2). The 'fruit-veg-sweets-snacks' pattern also showed positive associations with obesity and central obesity in age-adjusted analyses but these were fully attenuated following adjustment for potential confounders; the key confounders accounting for this attenuation were SLI and education. Lower quintiles of intake of the 'cerealssavoury foods' pattern were associated with lower odds of being obese and centrally obese, while the highest quintile of intake was associated with higher odds of obesity, among both men and women. After adjusting for additional confounding variables, the OR were markedly attenuated for the highest quintile group but among quintiles 2 and 3 , indicating moderate intake, lower odds of obesity were still apparent among both men and women. Consistent findings were found for central obesity among men but not women. Similar patterns of associations were observed in analyses taking the sib-pair data structure into account, with no statistical evidence of difference in associations within and between sib-pairs.

\section{Sensitivity analysis}

We conducted several sensitivity analyses to evaluate the consistency of the dietary patterns and the robustness of their associations with anthropometric indicators.

Using a more conservative cut-off of 0.3 for factor loadings, we obtained the following three components: component 1 retained positive loadings on rice, rice (mixed dishes), coffee, condiments and soups, and negative loadings on potato, other vegetables and cooked milk products; component 2 retained positive loadings only on fruits, snacks and sweets; and component 3 remained the same. To check the internal validity of these dietary patterns, we randomly divided the data set into two halves and carried out the same statistical procedures to obtain dietary patterns from each, using both $0 \cdot 15$ and $0 \cdot 3$ as cut-offs. In addition, to assess pattern consistency, we restricted the final factor solutions to three, four, five 


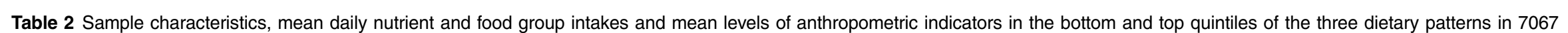
participants in the Indian Migration Study, 2006

\begin{tabular}{|c|c|c|c|c|c|c|c|c|c|c|c|c|c|c|}
\hline & \multicolumn{4}{|c|}{ 'Cereals-savoury foods' pattern $\ddagger$} & \multicolumn{4}{|c|}{ 'Fruit-veg-sweets-snacks' pattern $\ddagger$} & \multicolumn{4}{|c|}{ 'Animal-food’ pattern $\ddagger$} & & \\
\hline & \multicolumn{2}{|c|}{ Q1 (n 1353) } & \multicolumn{2}{|c|}{$\mathrm{Q} 5(n$ 1275) } & \multicolumn{2}{|c|}{ Q1 ( $n$ 1248) } & \multicolumn{2}{|c|}{$\mathrm{Q} 5(n$ 1361) } & \multicolumn{2}{|c|}{ Q1 $(n$ 1314) } & \multicolumn{2}{|c|}{$\mathrm{Q} 5(n$ 1313) } & \multicolumn{2}{|c|}{ Total } \\
\hline & Mean or $n$ & SD or $\%$ & Mean or $n$ & SD or $\%$ & Mean or $n$ & SD or $\%$ & Mean or $n$ & SD or $\%$ & Mean or $n$ & SD or $\%$ & Mean or $n$ & SD or \% & Mean or $n$ & SD or $\%$ \\
\hline \multicolumn{15}{|l|}{ Sample characteristics } \\
\hline Age (years) & 43.3 & 8.7 & $43.7 \dagger$ & 8.9 & $44 \cdot 4$ & $10 \cdot 0$ & $37.8 \dagger$ & $10 \cdot 1$ & 39.9 & $10 \cdot 9$ & $40.7^{\mathrm{NS}}$ & $9 \cdot 8$ & $40 \cdot 8$ & $10 \cdot 4$ \\
\hline Female§ & 488 & 34.5 & $558^{*}$ & 39.5 & 650 & $46 \cdot 0$ & $456+$ & $32 \cdot 3$ & 704 & 49.8 & $447 \dagger$ & $31 \cdot 6$ & 2944 & 41.7 \\
\hline Illiterate§ & 87 & $6 \cdot 2$ & $85^{N S}$ & $6 \cdot 0$ & 314 & $22 \cdot 2$ & $34 \dagger$ & $2 \cdot 4$ & 75 & $5 \cdot 3$ & $107^{\star}$ & 7.8 & 641 & $9 \cdot 1$ \\
\hline \multirow{2}{*}{\multicolumn{15}{|c|}{ Place of residence§ }} \\
\hline & & & & & & & & & & & & & & \\
\hline Lucknow & 1333 & $94 \cdot 3$ & 6 & 0.4 & 149 & $10 \cdot 5$ & 427 & $30 \cdot 2$ & 579 & $41 \cdot 0$ & 146 & $10 \cdot 3$ & 2000 & $28 \cdot 3$ \\
\hline Nagpur & 80 & $5 \cdot 7$ & 30 & $2 \cdot 1$ & 113 & 8.0 & 537 & 38.0 & 451 & 31.9 & 282 & $20 \cdot 0$ & 1640 & $23 \cdot 2$ \\
\hline Hyderabad & 0 & 0 & 511 & $36 \cdot 2$ & 762 & 53.9 & 231 & $16 \cdot 4$ & 193 & 13.7 & 583 & 41.3 & 1995 & 28.2 \\
\hline Bangalore & 1 & 0.1 & $866 \dagger$ & 61.3 & 390 & 27.6 & $218 \dagger$ & 15.4 & 191 & 13.5 & $402 \dagger$ & 28.5 & 1432 & 20.3 \\
\hline \multicolumn{15}{|l|}{ Migration status§ } \\
\hline Rural & 428 & 31.0 & 378 & $28 \cdot 0$ & 605 & $48 \cdot 6$ & 352 & $26 \cdot 8$ & 389 & 29.5 & 388 & 29.9 & 2111 & 32.4 \\
\hline Migrant & 403 & $29 \cdot 2$ & 424 & 31.4 & 353 & $28 \cdot 3$ & 397 & $30 \cdot 2$ & 421 & 31.9 & 412 & $31 \cdot 8$ & 2112 & 32.4 \\
\hline Urban & 549 & 39.8 & $547 \dagger$ & 40.6 & 288 & $23 \cdot 1$ & $564 \dagger$ & 43.0 & 510 & 38.6 & $497 \dagger$ & 38.3 & 2287 & 35.1 \\
\hline Current smokers§ & 369 & $26 \cdot 1$ & $226 \dagger$ & $16 \cdot 0$ & 285 & $20 \cdot 2$ & $351^{*}$ & 24.8 & 219 & $15 \cdot 5$ & $403 \dagger$ & $28 \cdot 5$ & 1562 & $22 \cdot 1$ \\
\hline Current drinkers§ & 173 & $12 \cdot 2$ & $281 \dagger$ & 19.9 & 322 & 22.8 & $195 \dagger$ & 13.8 & 66 & 4.7 & $409 \dagger$ & 29.0 & 1144 & $16 \cdot 2$ \\
\hline Physical activity (MET-h/d) & 39.0 & 4.1 & $38.4 \dagger$ & $4 \cdot 3$ & 38.4 & 5.0 & $39.5 \dagger$ & 4.9 & 38.9 & 4.5 & $38.8^{\mathrm{NS}}$ & 4.8 & 38.9 & 4.6 \\
\hline \multicolumn{15}{|l|}{ Nutrient intake (per day) } \\
\hline Energy (kJ) & 11949 & 3904 & $14157 \dagger$ & 4190 & 8539 & 2612 & $16833 \dagger$ & 4081 & 11470 & 3991 & $14322 \dagger$ & 4363 & 12128 & 4194 \\
\hline Energy (kcal) & 2855.8 & 933.0 & $3383.6 \dagger$ & $1001 \cdot 4$ & 2040.9 & $624 \cdot 2$ & $4023 \cdot 3 \dagger$ & $975 \cdot 3$ & $2741 \cdot 3$ & 953.9 & $3423.1 \dagger$ & $1042 \cdot 9$ & 2898.6 & $1002 \cdot 3$ \\
\hline Protein \% \% & 12.4 & 1.1 & $10.8 \dagger$ & 1.3 & 11.1 & 1.4 & $11.0 \dagger$ & 1.3 & 11.2 & 1.3 & $11.9 \dagger$ & 1.6 & 11.3 & 1.4 \\
\hline Carbohydrate \%॥ & 61.7 & $4 \cdot 3$ & $62 \cdot 4^{*}$ & 5.5 & $65 \cdot 8$ & $6 \cdot 2$ & $60.9 \dagger$ & 4.6 & 63.7 & $5 \cdot 0$ & $60.0 \dagger$ & $5 \cdot 4$ & 63.1 & $5 \cdot 4$ \\
\hline Fat \% & 5.7 & 4.2 & $26 \cdot 5 \dagger$ & 5.0 & $22 \cdot 8$ & $5 \cdot 6$ & $28.0 \dagger$ & 4.3 & $25 \cdot 3$ & 5.1 & $27.8 \dagger$ & 4.8 & $25 \cdot 5$ & $5 \cdot 0$ \\
\hline Saturated fat \%॥ & 8.2 & $2 \cdot 2$ & $8.5 \dagger$ & 2.4 & 7.1 & 2.6 & $8.4 \dagger$ & 2.3 & 7.5 & 2.5 & $8.3+$ & 2.4 & 7.7 & 2.4 \\
\hline Monounsaturated fat \% & 9.9 & 2.7 & $7.3+$ & 2.1 & 6.9 & 2.5 & $8.8 \dagger$ & 3.1 & 8.1 & 2.8 & $8 \cdot 3^{\star}$ & 2.9 & 8.0 & 2.8 \\
\hline Polyunsaturated fat \% $\%$ & $5 \cdot 4$ & $2 \cdot 3$ & $8.8 \dagger$ & 3.2 & $7 \cdot 1$ & 3.2 & $8.6 \dagger$ & 3.4 & 7.6 & 3.5 & $8.9 \dagger$ & 3.5 & 7.8 & 3.4 \\
\hline Fibre $(\mathrm{g})$ & 14.9 & $5 \cdot 8$ & $16 \cdot 3 \mathrm{t}$ & 7.0 & $8 \cdot 7$ & 3.8 & $21.1 \dagger$ & 6.4 & $14 \cdot 4$ & 6.0 & $16 \cdot 3 \dagger$ & 6.7 & $14 \cdot 3$ & 6.4 \\
\hline Folate $(\mu \mathrm{g})$ & 398.0 & $142 \cdot 7$ & $415 \cdot 3^{\mathrm{NS}}$ & $167 \cdot 2$ & 226.5 & 83.0 & $516 \cdot 6 \dagger$ & 164.0 & 373.9 & $158 \cdot 3$ & $406 \cdot 2 \dagger$ & $147 \cdot 7$ & 362.4 & 150.4 \\
\hline Food group intake $(\mathrm{g} / \mathrm{d})$ & & & & & & & & & & & & & & \\
\hline Whole grains & $270 \cdot 1$ & 105.8 & $229.4 \dagger$ & $272 \cdot 2$ & 183.3 & $204 \cdot 8$ & $258.8 \dagger$ & 186.7 & $222 \cdot 4$ & $142 \cdot 4$ & $219 \cdot 6^{\mathrm{NS}}$ & $225 \cdot 0$ & 225.1 & 193.1 \\
\hline Whole/refined grains (mixed dishes) & $53 \cdot 9$ & $60 \cdot 2$ & $111.9 \dagger$ & 73.1 & $61 \cdot 2$ & 61.9 & $97.4 \dagger$ & $89 \cdot 0$ & $55 \cdot 6$ & 55.4 & $93 \cdot 3 \dagger$ & $81 \cdot 1$ & $75 \cdot 3$ & $74 \cdot 1$ \\
\hline Plain rice & $136 \cdot 1$ & $116 \cdot 1$ & $716.0 \dagger$ & $409 \cdot 1$ & $549 . \overline{7}$ & $345 \cdot 1$ & $461 \cdot 4^{\mathrm{NS}}$ & $347 \cdot 4$ & $332 \cdot 3$ & 269.8 & $612 \cdot 1 \dagger$ & $392 \cdot 8$ & 463.7 & 353.7 \\
\hline Rice (mixed dishes) & 45.7 & 42.4 & $206 \cdot 1 \dagger$ & 144.7 & 73.8 & $77 \cdot 2$ & $141.6 \dagger$ & 126.3 & 71.8 & 64.4 & $149.0 \dagger$ & 140.1 & $102 \cdot 4$ & $103 \cdot 3$ \\
\hline Western cereals & 4.7 & $9 \cdot 2$ & $7.5 \dagger$ & 12.7 & 1.7 & 3.7 & $12.5 \dagger$ & 17.5 & 9.1 & $15 \cdot 3$ & $6.1 \dagger$ & 10.0 & 5.9 & 10.9 \\
\hline Pulses and legumes & 347.6 & 170.5 & $278.6 \dagger$ & 200.1 & $154 \cdot 6$ & 113.4 & $361.8 \dagger$ & 209.9 & 321.3 & 183.5 & $254.1 \mathrm{t}$ & 180.4 & 269.8 & 181.5 \\
\hline Green leafy vegetables & 44.0 & $46 \cdot 7$ & $55.1 \dagger$ & $46 \cdot 0$ & 37.9 & $42 \cdot 0$ & $56.1 \dagger$ & $55 \cdot 2$ & $48 \cdot 6$ & $58 \cdot 9$ & $47 \cdot 3^{\mathrm{NS}}$ & 38.4 & 44.1 & $43 \cdot 1$ \\
\hline Potato & $100 \cdot 0$ & $51 \cdot 2$ & $9 \cdot 1 \dagger$ & $10 \cdot 3$ & $13 \cdot 2$ & 29.7 & $41.2 \dagger$ & $47 . \overline{5}$ & 37.8 & 43.0 & $21 \cdot 1 \dagger$ & 32.5 & 33.1 & 45.4 \\
\hline Other vegetables & 281.8 & $142 \cdot 2$ & $97.3 \dagger$ & 65.7 & 64.0 & 50.3 & $237.5 \dagger$ & 154.6 & 183.5 & 135.4 & $129.2 \dagger$ & 100.5 & $152 \cdot 2$ & 121.0 \\
\hline Fruits & 351.4 & 250.0 & $336.8^{\mathrm{NS}}$ & 255.8 & 128.4 & 84.5 & $616 \cdot 2 \dagger$ & 340.9 & 330.4 & 245.1 & $384.9+$ & 276.6 & 332.2 & 259.7 \\
\hline Fruit juice & 13.7 & 35.7 & $21.0 \dagger$ & 40.0 & 4.7 & 8.4 & $38.3 \dagger$ & 94.1 & 24.3 & 83.3 & $21 \cdot 7^{\mathrm{NS}}$ & 44.8 & 17.3 & 47.9 \\
\hline Milk and milk products & $232 \cdot 8$ & $220 \cdot 7$ & $254.7 \dagger$ & 263.8 & $121 \cdot 2$ & $164 \cdot 7$ & $265.8 \dagger$ & $288 \cdot 3$ & $193 \cdot 8$ & $203 \cdot 3$ & $214 \cdot 3^{\mathrm{NS}}$ & $239 \cdot 0$ & $196 \cdot 1$ & $227 \cdot 0$ \\
\hline Milk and milk products (mixed dishes) & 37.7 & $47 \cdot 3$ & $10.2 \dagger$ & 19.6 & 4.8 & 9.7 & $40.6 \dagger$ & 53.1 & $30 \cdot 3$ & 36.7 & $19.6 \dagger$ & $39 \cdot 3$ & 21.6 & 33.0 \\
\hline Red meats & 4.6 & 11.3 & $17.5 \dagger$ & 24.6 & 11.5 & $17 \cdot 3$ & $13.8^{\star}$ & 22.9 & 0.2 & 1.3 & $35.4 \dagger$ & 37.7 & 11.6 & 22.1 \\
\hline Poultry & 5.9 & $16 \cdot 1$ & $34.8 \dagger$ & 53.6 & $16 \cdot 1$ & $27 \cdot 4$ & $24.2 \dagger$ & $47 \cdot 3$ & 0.3 & 1.8 & $59.1 \dagger$ & 68.0 & $18 \cdot 6$ & 38.4 \\
\hline Fish and seafood & 6.5 & 35.5 & $11.3 \dagger$ & $24 \cdot 2$ & 6.4 & 13.9 & $12.6 \dagger$ & $40 \cdot 7$ & 0.1 & 0.9 & $29.9+$ & $50 \cdot 6$ & 8.9 & $25 \cdot 8$ \\
\hline Eggs & 4.3 & $10 \cdot 6$ & $9.0 \dagger$ & 13.8 & $5 \cdot 3$ & 7.5 & $9.0 \dagger$ & 14.4 & 0.3 & 1.3 & $16.7 \dagger$ & 18.5 & 6.6 & $11 \cdot 2$ \\
\hline Other non-vegetarian & 0.0 & 0.3 & $1.0 \dagger$ & 4.0 & 0.4 & 1.7 & $0.8 \dagger$ & 4.5 & 0.0 & 0.0 & $2.0 \dagger$ & 5.9 & 0.6 & 3.0 \\
\hline Mutton or chicken & 1.9 & 8.1 & $20.0 \dagger$ & 51.9 & 5.9 & 20.7 & $13.7 \dagger$ & 32.1 & 0.2 & 1.7 & $30.0 \dagger$ & 55.6 & 8.4 & 27.9 \\
\hline Fats & 5.2 & $5 \cdot 1$ & $3.0+$ & $5 \cdot 1$ & 1.1 & 3.2 & $4.0 \dagger$ & 5.5 & 4.3 & 5.5 & $2.3 \dagger$ & 4.1 & 2.9 & 4.7 \\
\hline Sugars & 8.3 & 10.9 & $2.0 \dagger$ & $5 \cdot 1$ & 0.5 & $1 \cdot 6$ & $9.2 \dagger$ & $10 \cdot 7$ & 6.7 & $9 \cdot 0$ & $3 \cdot 1 \dagger$ & $7 \cdot 0$ & $4 \cdot 3$ & 7.5 \\
\hline Alcohol & $7 \cdot 1$ & $62 \cdot 2$ & $20.0 \dagger$ & 98.8 & 21.9 & 103.4 & $12 \cdot 2 \dagger$ & 61.1 & $2 \cdot 1$ & $19 \cdot 8$ & $27.8 \dagger$ & $94 \cdot 3$ & 11.9 & 64.9 \\
\hline Tea & 352.2 & 258.2 & $191.4 \dagger$ & $170 \cdot 1$ & 208.5 & 195.7 & $264.9 \dagger$ & $205 \cdot 1$ & 213.7 & 160.2 & $260.9 \dagger$ & 239.9 & 242.7 & 201.9 \\
\hline Coffee & $2 \cdot \overline{7}$ & $12 \cdot 7$ & $150 \cdot 4$ & $153.7 \dagger$ & 74.1 & 133.0 & 32.4 & $78.2 \dagger$ & 30.7 & 78.9 & $60.4 \dagger$ & $102 \cdot 8$ & 44.1 & 96.9 \\
\hline
\end{tabular}


and six factors, again with both cut-offs. From these analyses, the 'fruit-veg-sweets-snacks' dietary pattern emerged as the least consistent. It showed considerable variability across analyses, although positive loadings on fruit, snacks and sweets remained through all analyses.

The 'cereals-savoury foods' dietary pattern loaded positively on rice and condiments, and negatively on potato and other vegetables, consistently across all sensitivity analyses. This pattern was predominantly eaten in the South Indian states of Hyderabad and Bangalore, and was eaten to a much lesser extent in the North Indian states of Lucknow and Nagpur (Table 2). In particular, factory location was the confounder driving the attenuation of the association of the highest quintile of the 'cereals-savoury foods' pattern with BMI and waist circumference. Since it is possible that there is residual confounding by region in this association, we restricted the analysis to Lucknow and Nagpur (only one person in the bottom-most quintile in the south made this analysis untenable in the southern states). The inverse association of this dietary pattern with obesity became slightly stronger, with multivariate OR for increasing quintiles of intake being 0.69 (95\% CI $0.50,0.96), 0.38$ (95\% CI 0.23, 0.62), 0.67 (95\% CI $0.36,1.24)$ and 1.22 (95\% CI $0.35,4.20$; $P$ value for trend $=0.007$ ) for men, and 0.79 (95\% CI 0.54 , $1 \cdot 14$ ), 0.32 (95\% CI $0 \cdot 17,0.58), 0.40$ (95\% CI $0 \cdot 18,0.89$ ) and $0.97(95 \% \mathrm{CI} 0 \cdot 18,5 \cdot 27 ; P$ value for trend $=0.001)$ for women. Similar findings were observed for central obesity.

The 'animal-food' dietary pattern emerged as the most consistent and generalizable pattern, remaining the same in all sensitivity analyses. We compared those who ate any non-dairy animal food (called a 'non-vegetarian diet' in India) with those who did not eat any non-dairy animal food (called a 'lacto-vegetarian diet' in India), in order to examine whether a simple vegetarian/non-vegetarian classification would work just as well in terms of strength of association with obesity. The results were in a similar direction as, albeit slightly weaker than, those found when the 'animal-food' pattern was used as the exposure. Being in the top quartile of 'non-vegetarian' food consumption relative being a 'lacto-vegetarian' was associated with increased odds of obesity (men: OR $=1 \cdot 69 ; 95 \%$ CI $1 \cdot 26$, 2.27; $P$ value for trend <0.001; women: $\mathrm{OR}=1.55 ; 95 \% \mathrm{CI}$ $1 \cdot 13,2 \cdot 12 ; P$ value for trend $=0.025)$ and central obesity (men: $\mathrm{OR}=1.46 ; 95 \%$ CI 1.04, 2.06; $P$ value for trend $=$ 0.015; women: $\mathrm{OR}=1.95 ; 95 \%$ CI $1.40,2.70 ; P$ value for trend <0.001).

It is possible for an individual to have similar scores on two or three dietary patterns, even though they are statistically independent. Since the 'fruit-veg-sweets-snacks' pattern was not consistent and was not associated with either outcome in adjusted analyses, we examined the associations of the joint classifications of the other two patterns with the outcomes. Among women, being in the highest quintile of intake of the 'animal-foods' pattern and lowest quintile of the 'cereals-savoury foods' pattern was 
Table 3 Odds ratios and $95 \%$ confidence intervals $\ddagger$ of anthropometric indicators according to quintiles of the three dietary patterns for 3823 men, Indian Migration Study, 2006

\begin{tabular}{|c|c|c|c|c|c|c|c|c|c|c|c|}
\hline \multirow[b]{2}{*}{ Outcome variable } & \multirow[b]{2}{*}{ Model } & \multirow[b]{2}{*}{ Q1§ } & \multicolumn{2}{|r|}{ Q2 } & \multicolumn{2}{|r|}{ Q3 } & \multicolumn{2}{|r|}{ Q4 } & \multicolumn{2}{|r|}{ Q5 } & \multirow[b]{2}{*}{$P$ for trenc } \\
\hline & & & OR & $95 \% \mathrm{Cl}$ & OR & $95 \% \mathrm{Cl}$ & OR & $95 \% \mathrm{Cl}$ & OR & $95 \% \mathrm{Cl}$ & \\
\hline \multicolumn{12}{|c|}{ 'Cereals-savoury foods' dietary pattern } \\
\hline \multirow[t]{2}{*}{ Obesity } & Age-adjusted & 1.00 & 0.62 & $0.47,0.83$ & 0.51 & $0.38,0.69$ & 0.92 & $0.71,1 \cdot 21$ & 1.47 & $1.13,1.90$ & 0.001 \\
\hline & Fully adjustedll & 1.00 & 0.63 & $0.45,0.88$ & 0.55 & $0.36,0.85$ & 0.84 & $0.53,1.34$ & 1.14 & $0.67,1.94$ & 0.330 \\
\hline \multirow[t]{2}{*}{ Central obesity } & Age-adjusted & 1.00 & 0.34 & $0.24,0.48$ & 0.26 & $0.18,0.37$ & 0.43 & $0.31,0.59$ & 0.73 & $0.55,0.98$ & 0.041 \\
\hline & Fully adjustedll & 1.00 & 0.36 & $0.24,0.54$ & 0.38 & $0.22,0.65$ & 0.56 & $0.32,0.99$ & 0.97 & $0.51,1.84$ & 0.796 \\
\hline \multicolumn{12}{|c|}{ 'Fruit-veg-sweets-snacks' dietary pattern } \\
\hline \multirow[t]{2}{*}{ Obesity } & Age-adjusted & 1.00 & 1.38 & $1.03,1.85$ & 1.53 & $1.15,2.05$ & 1.65 & $1 \cdot 24,2 \cdot 21$ & 1.68 & $1 \cdot 26,2 \cdot 24$ & $<0.001$ \\
\hline & Fully adjustedll & 1.00 & 0.93 & $0.65,1.33$ & 0.95 & $0.66,1.37$ & 0.92 & $0.63,1.34$ & 0.79 & $0.51,1.22$ & 0.349 \\
\hline \multirow[t]{2}{*}{ Central obesity } & Age-adjusted & 1.00 & 1.86 & $1.29,2.67$ & $2 \cdot 17$ & $1.51,3.12$ & $2 \cdot 15$ & $1.50,3.08$ & 2.39 & $1.67,3.42$ & $<0.001$ \\
\hline & Fully adjustedll & 1.00 & $1 \cdot 13$ & $0.74,1.72$ & $1 \cdot 15$ & $0.75,1.78$ & 1.07 & $0.69,1.68$ & 0.98 & $0.58,1.63$ & 0.780 \\
\hline \multicolumn{12}{|c|}{ 'Animal-food' dietary pattern } \\
\hline \multirow[t]{2}{*}{ Obesity } & Age-adjusted & 1.00 & 0.84 & $0.63,1.13$ & 1.00 & $0.75,1.33$ & 1.21 & $0.91,1.62$ & 1.57 & $1 \cdot 19,2.07$ & $<0.001$ \\
\hline & Fully adjustedll & 1.00 & 0.97 & $0.70,1.35$ & $1 \cdot 31$ & $0.94,1.83$ & 1.36 & $0.97,1.90$ & 1.68 & $1.20,2.36$ & 0.001 \\
\hline \multirow[t]{2}{*}{ Central obesity } & Age-adjusted & 1.00 & 0.93 & $0.65,1.32$ & 0.95 & $0.67,1.34$ & 1.26 & $0.89,1.78$ & 1.46 & $1.05,2.05$ & 0.004 \\
\hline & Fully adjustedll & 1.00 & $1 \cdot 10$ & $0.75,1.62$ & 1.27 & $0.85,1.89$ & 1.75 & $1.17,2.63$ & 1.80 & $1.20,2.70$ & 0.001 \\
\hline
\end{tabular}

¥Using mixed-effects logistic regression analysis.

$\S \mathrm{Q} 1$ is the lowest quintile (referent category) and Q5 is the highest quintile.

$\|$ Adjusted for age, education, standard of living, factory location, migration status, tobacco consumption, alcohol consumption, total energy intake and physical activity.

Table 4 Odds ratios and $95 \%$ confidence intervals $\ddagger$ of anthropometric indicators according to quintiles of the three dietary patterns for 2758 women, Indian Migration Study, 2006

\begin{tabular}{|c|c|c|c|c|c|c|c|c|c|c|c|}
\hline \multirow[b]{2}{*}{ Outcome variable } & \multirow[b]{2}{*}{ Model } & \multirow[b]{2}{*}{ Q1§ } & \multicolumn{2}{|r|}{ Q2 } & \multicolumn{2}{|r|}{ Q3 } & \multicolumn{2}{|r|}{ Q4 } & \multicolumn{2}{|r|}{ Q5 } & \multirow[b]{2}{*}{$P$ for trend } \\
\hline & & & OR & $95 \% \mathrm{Cl}$ & OR & $95 \% \mathrm{Cl}$ & OR & $95 \% \mathrm{Cl}$ & OR & $95 \% \mathrm{Cl}$ & \\
\hline \multicolumn{12}{|c|}{ ‘Cereals-savoury foods' dietary pattern } \\
\hline \multirow[t]{2}{*}{ Obesity } & Age-adjusted & 1.00 & 0.61 & $0.44,0.84$ & 0.61 & $0.45,0.84$ & 1.01 & $0.75,1.37$ & 1.40 & $1.02,1.92$ & 0.001 \\
\hline & Fully adjustedll & 1.00 & 0.66 & $0.46,0.94$ & 0.59 & $0.38,0.93$ & 0.67 & $0.41,1 \cdot 10$ & 0.69 & $0.39,1.23$ & 0.389 \\
\hline \multirow[t]{2}{*}{ Central obesity } & Age-adjusted & 1.00 & 0.69 & $0.50,0.95$ & 0.86 & $0.63,1.17$ & 1.00 & $0.73,1.35$ & 1.19 & $0.87,1.64$ & 0.039 \\
\hline & Fully adjustedll & 1.00 & 0.80 & $0.55,1.15$ & 1.04 & $0.66,1.64$ & 0.93 & $0.56,1.56$ & 0.95 & $0.53,1.70$ & 0.879 \\
\hline \multicolumn{12}{|c|}{ 'Fruit-veg-sweets-snacks' dietary pattern } \\
\hline \multirow[t]{2}{*}{ Obesity } & Age-adjusted & 1.00 & 1.11 & $0.83,1.49$ & 1.42 & $1.05,1.93$ & 1.61 & $1 \cdot 18,2 \cdot 19$ & 1.57 & $1 \cdot 12,2 \cdot 19$ & $<0.001$ \\
\hline & Fully adjustedll & 1.00 & 0.82 & $0.59,1.14$ & 1.00 & $0.69,1.45$ & 1.09 & $0.74,1.61$ & 1.06 & $0.65,1.72$ & 0.384 \\
\hline \multirow[t]{2}{*}{ Central obesity } & Age-adjusted & 1.00 & 1.20 & $0.90,1.60$ & 1.32 & $0.98,1.78$ & 1.41 & $1.04,1.90$ & 1.22 & $0.88,1.69$ & 0.092 \\
\hline & Fully adjustedll & 1.00 & 0.87 & $0.62,1.22$ & 0.86 & $0.59,1.26$ & 0.91 & $0.61,1.36$ & 0.68 & $0.41,1.12$ & 0.288 \\
\hline \multicolumn{12}{|c|}{ 'Animal-food' dietary pattern } \\
\hline \multirow[t]{2}{*}{ Obesity } & Age-adjusted & 1.00 & $1 \cdot 30$ & $0.98,1.73$ & $1 \cdot 22$ & $0.90,1.65$ & 1.32 & $0.97,1.79$ & $2 \cdot 76$ & $1.97,3.87$ & $<0.001$ \\
\hline & Fully adjusted\|lI & 1.00 & 1.34 & $0.99,1.80$ & 1.44 & $1.04,1.99$ & 1.22 & $0.87,1.70$ & $2 \cdot 30$ & $1.58,3.35$ & $<0.001$ \\
\hline \multirow[t]{2}{*}{ Central obesity } & Age-adjusted & 1.00 & 1.02 & $0.77,1.36$ & $1 \cdot 20$ & $0.89,1.62$ & 1.45 & $1.07,1.97$ & 2.44 & $1.75,3.40$ & $<0.001$ \\
\hline & Fully adjustedll & 1.00 & 1.04 & $0.76,1.42$ & 1.38 & $0.98,1.93$ & 1.39 & $0.98,1.98$ & $2 \cdot 27$ & $1.54,3.36$ & $<0.001$ \\
\hline
\end{tabular}

‡Using mixed-effects logistic regression analysis.

$\S Q 1$ is the lowest quintile (referente category) and Q5 is the highest quintile.

IIAdjusted for age, education, standard of living, factory location, migration status, tobacco consumption, alcohol consumption, total energy intake and physical activity.

associated with a ninefold increase in the odds of obesity, relative to being in the lowest quintile of the 'animal-foods' pattern and highest quintile of the 'cereals-savoury foods' pattern $(\mathrm{OR}=9 \cdot 16 ; 95 \% \mathrm{CI} 1 \cdot 44,58 \cdot 13 ; P$ value for trend $<0 \cdot 001)$. No other meaningful significant associations were found. Likelihood ratio tests were done, comparing nested models with and without an interaction term between the two dietary patterns. With the exception of central obesity among men, no significant interactions were found between the patterns, indicating that the associations of the two pattern scores with obesity among both men and women, and with central obesity among women, are independent of one another.

\section{Discussion}

Three dietary patterns, 'cereals-savoury foods', 'fruit-vegsweets-snacks' and 'animal-food', were identified through factor analysis of dietary intake data in a large multi-centre cross-sectional study in India. We found positive, graded associations across quintiles of the 'animal-food' pattern 


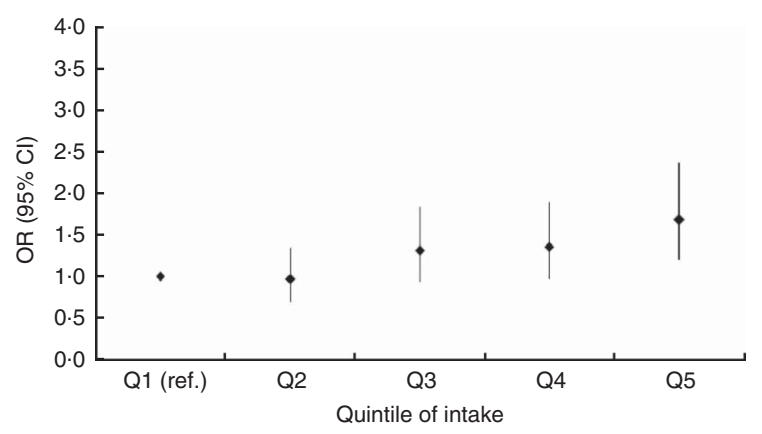

Fig. 1 Odds ratios, with $95 \%$ confidence intervals represented by vertical bars, for the association between obesity (BMI $\geq 25.0 \mathrm{~kg} / \mathrm{m}^{2}$ ) and quintiles of the 'animal-food' dietary pattern among 3823 men, adjusting for potential confounders, Indian Migration Study, 2006 (ref., referent category)

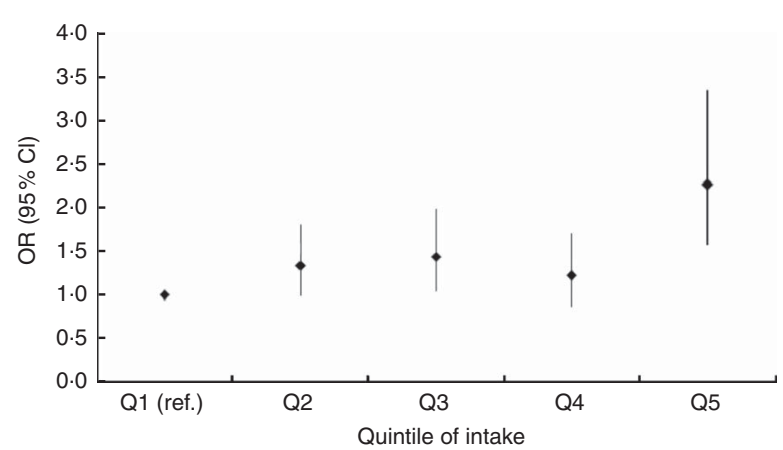

Fig. 2 Odds ratios, with $95 \%$ confidence intervals represented by vertical bars, for the association between obesity (BMI $\geq 25.0 \mathrm{~kg} / \mathrm{m}^{2}$ ) and quintiles of the 'animal-food' dietary pattern among 2758 women, adjusting for potential confounders, Indian Migration Study, 2006 (ref., referent category)

with both obesity and central obesity that were not explained by confounding factors, among both men and women, and were consistent in sensitivity analyses. This pattern was a stronger predictor of these outcomes than a simple vegetarian/non-vegetarian classification. We also showed that moderate intake of the 'cereals-savoury foods' pattern was associated with reduced odds of obesity and central obesity, and this association was strengthened after restricting the analysis to the northern states, indicating possible residual confounding by region. The associations of these dietary patterns with the outcomes were independent of one another, except for central obesity among men.

Newby and Tucker ${ }^{(13)}$ reviewed almost 100 studies, carried out in different countries and published since 1980, that have used some data reduction method to identify dietary patterns. Various dietary patterns have been identified, the most consistently found being the 'prudent' pattern (high on fruit, vegetables, legumes, fish, low-fat dairy and whole grains) and the 'Western' pattern (high on red and processed meats, eggs, refined grains, sugar and fast foods), both first identified by Slattery et al. in an
American population ${ }^{(26)}$. Since then, these two patterns have been identified in several other populations, either together or individually, in North America ${ }^{(5,6,8,9,27)}$ and Europe $^{(28-32)}$, and occasionally in other countries such as Brazil $^{(33)}$. Another pattern commonly identified in North America $^{(11,34,35)}$ and Europe ${ }^{(31,36-39)}$ is a 'high sweetsintake' pattern ${ }^{(13)}$. Some studies have found the 'Western' pattern to be positively and the 'prudent' pattern to be inversely associated with obesity ${ }^{(27)}$, CHD risk ${ }^{(27,40)}$, type 2 diabetes risk ('Western' pattern) ${ }^{(6)}$ and all-cause and CVD mortality ('prudent' pattern) ${ }^{(28)}$. The 'high sweets-intake' pattern has not shown consistent associations with any cardio-metabolic risk factors and end points ${ }^{(13)}$.

The patterns we identified do not map directly on to the 'prudent-healthy'/Western-unhealthy' dichotomy, although elements of overlap exist. For instance, the 'fruitveg-sweets-snacks' pattern has aspects of the 'prudent' pattern, such as high loadings on fruits and vegetables, which have been associated with decreased cardiometabolic risk ${ }^{(9,41,42)}$. However, it also has elements of the 'Western' pattern, in particular high intakes of snacks, sugars and sweets, which have been associated with increased cardio-metabolic risk ${ }^{(9,41)}$. This coexistence of healthy and unhealthy dietary factors in one pattern could be a reason for the null findings with the 'fruit-veg-sweets-snacks' pattern.

The 'animal-food' pattern found in the present study has red meats and eggs, similar to the 'Western' pattern. Processed and unprocessed red meat intakes have independently been shown to be associated with increased obesity risk ${ }^{(41)}$. However, other elements of the 'Western' pattern such as refined grains and fast foods are not part of the 'animal-food' pattern found here. In addition, some foods loading heavily on the 'prudent' pattern, such as fish, which has been associated with reduced weight gain relative to meat intake ${ }^{(43)}$, are also part of the 'animal-food' pattern. Other studies, however, have found predominantly animal-food patterns. For instance, Masaki et $a l .{ }^{(44)}$ found a 'meat' pattern in Japan, which loaded heavily on pork, beef and chicken, and negatively on certain fruits; but in univariate analysis, this was not associated with BMI. In another Japanese study, Ogura et $a l .{ }^{(45)}$ found a pattern that was high in beef, pork and chicken, while Chen et $a l .^{(46)}$ found a pattern in an American population with higher contributions from red meat, processed meat and beans. Neither study evaluated associations of these dietary patterns with obesity. One of the patterns found by Maskarinec et al. ${ }^{(47)}$ in Hawaii loaded heavily on processed meat, red meat, fish, poultry and egg, in addition to fats and oils, and condiments, which is very similar to the 'animal-food' pattern found in our study. That study found a positive association between this 'meat' pattern and BMI, which is in line with our findings. It is possible that an 'animal-food' dietary pattern increases the risk of obesity through increased intake of animalprotein food sources. Re-doing the analysis with the 
'animal-food' pattern after including percentage of energy from protein as a covariate in the fully adjusted model attenuated the association with both obesity and central obesity, among both men and women (see online supplementary material, Supplemental Table 2). Several randomized controlled trials have shown high-protein diets to be associated with short-term weight loss; however the type of protein may be important, with plant sources of protein (nuts, legumes) being potentially more beneficial than animal sources (red meat) ${ }^{(48)}$. While the crosssectional nature of the data precludes a mediation analysis, further studies should explore the role of plant and animal sources of protein in weight loss and maintenance.

Ours is one of few studies that have used data reduction techniques to identify composite dietary patterns in India. A study conducted in ten Indian states found two dietary patterns from factor analysis of macro- and micronutrients: the 'energy' pattern and the 'vitamin' pattern ${ }^{(49)}$. However, associations of these factors with disease risk were not reported. Another study among women in West Bengal found three patterns, one of which (the 'vegetables, fruit and pulses' pattern) was similar to the 'fruit-veg-sweetssnacks' pattern found here, with the exception that it also loaded heavily on poultry and eggs ${ }^{(50)}$. This pattern, as in our study, was not associated with any anthropometric variable. A third study ${ }^{(51)}$ carried out in Delhi, Trivandrum and Mumbai found two patterns that had some parallels with the 'cereals-savoury foods' pattern, specifically with respect to loadings on cereal-based products, nuts, snacks and condiments, one of which was associated with central obesity, which is not consistent with our findings.

A review by Togo et $a l .{ }^{(52)}$ found mixed results among thirty studies evaluating the associations of dietary patterns with BMI or obesity, with ten studies finding a positive association with the high fatty, sweet or energy-dense patterns, four studies finding negative associations and eleven studies finding no association. Potential interactions with age and sex could explain some of this inconsistency ${ }^{(13)}$. It is also possible that regional differences in diet play a role. The first pattern identified in the present study was predominantly eaten in the southern cities, with the other two also showing distinct regional patterns. Lastly, differing cooking styles used in different countries and in different parts of one country might be contributing to some of the inconsistency. It could be that the way most dishes based on animal foods are cooked in India influences their impact on obesity risk, which is different from the way this pans out in the West. Further analysis exploring these potential interactions and culinary differences could clarify these findings.

India is in the middle of the nutrition transition ${ }^{(15)}$, shifting from diets high in cereals and fibre to diets high in sugar, fats and animal-source foods, concomitant with increases in obesity and chronic diseases ${ }^{(53)}$. A review of nationally representative surveys on diet and nutrition in India $^{(15)}$ found that between 1975 and 1995, while there was a gradual reduction in cereal grain consumption, there was an increase in intake of milk and milk products, animal products ('flesh foods') and fats and oils. A strong positive association between an 'animal-food' dietary pattern and obesity in an Indian population further strengthens evidence for the potential role of increased animal-source food consumption, as part of the nutrition transition, in the increasing prevalence of obesity in India. Some studies in the UK have found vegetarian and vegan diets to be associated with lower BMI and reduced weight gain relative to 'omnivorous ${ }^{(54)}$ or meat- and fish-based diets $^{(43)}$. With more than one-third of the Indian population being vegetarian ${ }^{(55)}$, there is an opportunity in India to explore the associations of vegetarian diets with health profiles to a greater extent than in countries where vegetarianism is not as prevalent.

Given the cross-sectional nature of the present study, it is possible that measurement error in the FFQ is differential with respect to obesity. If obese individuals are more likely to under-report animal-food intake due to social desirability, then the associations observed in our study would be underestimates of the true association between the 'animal-food' pattern and obesity. However, as the amount of bias potentially induced by this is not entirely predictable, this limitation must be kept in mind when interpreting the results of the study. It is possible that residual confounding occurred, despite controlling for several potential confounders, as was seen in stratified analysis by region. Although indicators of socio-economic status (SLI and education), physical activity and alcohol/ tobacco consumption were controlled for, which further strengthens the associations observed, it does not exclude the possibility that these dietary patterns might be proxy indicators of socio-economic status or specific lifestyles in this population. Like all cross-sectional studies, the data may be prone to reverse causation despite the exclusion of known diabetics. Lastly, these three dietary patterns explained only $28.6 \%$ of the total variance, and thus it is possible that other dietary patterns exist in this study population. However, the percentage of variance explained by specific factors needs cautious interpretation, as this figure will change considerably as the number of initial variables included in the factor analysis changes.

Despite its cross-sectional nature, the present study has several advantages. It was carried out in a large, national sample of Indian adults, in which information on regional meal patterns was captured using a valid and reliable FFQ developed for the Indian context. The validity study done for the FFQ found that it overestimated energy intake by $1711 \mathrm{~kJ}$ ( $409 \mathrm{kcal}$ ) compared with an average taken from the three $24 \mathrm{~h}$ recalls. Although this could compromise the accuracy of reported intake, for the purposes of the present study relative intake of different food groups was more important, hence this is not likely to significantly impact the findings.

The dietary patterns identified in the present study were distinct from the ones found in other countries, with a 
clear distinction emerging between plant food-based and animal food-based patterns, with the latter showing positive associations with obesity and central obesity. If these findings are confirmed by other studies in India, dietary guidelines could recommend limiting intakes of most animal-food items in preference to a predominantly plantbased diet. More studies examining longitudinal changes in obesity associated with dietary patterns specific to the Indian context, and examining possible interaction patterns, are however needed to clarify and build on the associations observed in the present study.

\section{Acknowledgements}

Financial support: The Indian Migration Study was funded by the Wellcome Trust (grant number GR070797MF). The funder had no role in the design, analysis or writing of this article. Conflict of interest: None. Authorship: L.B., A.V.B., M.V., D.P., K.S.R., Y.B.-S., G.D.S., S.K. and S.E. contributed to the design and conduct of the study. S.E., F.B.H. and A.S. designed the analysis of the study. A.S. conducted the analysis and drafted the manuscript. S.E. and F.B.H. contributed to the interpretation of results and helped write the manuscript. All authors provided feedback on the manuscript, contributed to final editing and approved the submitted version. Ethics of human subject participation: Ethical approval for the study was obtained from the All India Institute of Medical Sciences Ethics Committee (reference number A-60/4/8/2004).

\section{Supplementary material}

To view supplementary material for this article, please visit http://dx.doi.org/10.1017/S1368980015000312

\section{References}

1. Finucane MM, Stevens GA, Cowan MJ et al.; Global Burden of Metabolic Risk Factors of Chronic Diseases Collaborating Group (Body Mass Index) (2011) National, regional, and global trends in body-mass index since 1980: Systematic analysis of health examination surveys and epidemiological studies with 960 country-years and 9.1 million participants. Lancet 377, 557-567.

2. Hu FB, Rimm E, Smith-Warner SA et al. (1999) Reproducibility and validity of dietary patterns assessed with a foodfrequency questionnaire. Am J Clin Nutr 69, 243-249.

3. Millen BE, Quatromoni PA, Copenhafer DL et al. (2001) Validation of a dietary pattern approach for evaluating nutritional risk: the Framingham Nutrition Studies. J Am Diet Assoc 101, 187-194.

4. Hu FB (2008) Obesity Epidemiology. New York: Oxford University Press.

5. Fung TT, Rimm EB, Spiegelman D et al. (2001) Association between dietary patterns and plasma biomarkers of obesity and cardiovascular disease risk. Am J Clin Nutr 73, 61-67.

6. van Dam RM, Rimm EB, Willett WC et al. (2002) Dietary patterns and risk for type 2 diabetes mellitus in US men. Ann Intern Med 136, 201-209.
7. Hu FB (2002) Dietary pattern analysis: a new direction in nutritional epidemiology. Curr Opin Lipidol 13, 3-9.

8. Kerver JM, Yang EJ, Bianchi L et al. (2003) Dietary patterns associated with risk factors for cardiovascular disease in healthy US adults. Am J Clin Nutr 78, 1103-1110.

9. Schulze MB, Fung TT, Manson JE et al. (2006) Dietary patterns and changes in body weight in women. Obesity (Silver Spring) 14, 1444-1453.

10. Newby PK, Muller D, Hallfrisch J et al. (2003) Dietary patterns and changes in body mass index and waist circumference in adults. Am J Clin Nutr 77, 1417-1425.

11. Newby PK, Muller D, Hallfrisch J et al. (2004) Food patterns measured by factor analysis and anthropometric changes in adults. Am J Clin Nutr 80, 504-513.

12. McNaughton SA, Mishra GD, Stephen AM et al. (2007) Dietary patterns throughout adult life are associated with body mass index, waist circumference, blood pressure, and red cell folate. J Nutr 137, 99-105.

13. Newby PK \& Tucker KL (2004) Empirically derived eating patterns using factor or cluster analysis: a review. Nutr Rev 62, 177-203.

14. Iqbal R, Anand S, Ounpuu S et al. (2008) Dietary patterns and the risk of acute myocardial infarction in 52 countries: results of the INTERHEART study. Circulation 18, 1929-1937.

15. Shetty PS (2002) Nutrition transition in India. Public Health Nutr 5, 175-182.

16. Ebrahim S, Kinra S, Bowen L et al. (2010) The effect of ruralto-urban migration on obesity and diabetes in India: a crosssectional study. PLoS Med 7, e1000268.

17. Kinra S, Bowen LJ, Lyngdoh $\mathrm{T}$ et al. (2010) Sociodemographic patterning of non-communicable disease risk factors in rural India: a cross sectional study. BMJ 341, c4974.

18. Lyngdoh T, Kinra S, Shlomo YB et al. (2006) Sib-recruitment for studying migration and its impact on obesity and diabetes. Emerg Themes Epidemiol 3, 2.

19. Indian Consensus Group (1996) Indian consensus for prevention of hypertension and coronary heart disease. A joint scientific statement of Indian Society of Hypertension and International College of Nutrition. J Nutr Environ Med 6, 309-318.

20. World Health Organization (2011) Waist Circumference and Waist-Hip Ratio: Report of a WHO Expert Consultation, Geneva, 8-11 December 2008. Geneva: WHO.

21. Bowen L, Ebrahim S, De Stavola B et al. (2011) Dietary intake and rural-urban migration in India: a crosssectional study. PLoS One 6, e14822.

22. Bowen L, Bharathi AV, Kinra S et al. (2012) Development and evaluation of a semi-quantitative food frequency questionnaire for use in urban and rural India. Asia Pac J Clin Nutr 21, 355-360.

23. Parr CL, Veierød MB, Laake P et al. (2006) Test-retest reproducibility of a food frequency questionnaire (FFQ) and estimated effects on disease risk in the Norwegian Women and Cancer Study (NOWAC). Nutr J 5, 4.

24. Marchioni DML, Voci SM, de Lima FEL et al. (2007) Reproducibility of a food frequency questionnaire for adolescents. Cad Saude Publica 23, 2187-2196.

25. Bharathi AV, Kuriyan R, Kurpad AV et al. (2010) Assessment of physical activity using accelerometry, an activity diary, the heart rate method and the Indian Migration Study questionnaire in South Indian adults. Public Health Nutr 13, 47-53.

26. Slattery ML, Boucher KM, Caan BJ et al. (1998) Eating patterns and risk of colon cancer. Am J Epidemiol 148, 4-16.

27. Hu FB, Rimm EB, Stampfer MJ et al. (2000) Prospective study of major dietary patterns and risk of coronary heart disease in men. Am J Clin Nutr 72, 912-921.

28. Osler M, Heitmann BL, Gerdes LU et al. (2001) Dietary patterns and mortality in Danish men and women: a prospective observational study. BrJ Nutr 85, 219-225. 
29. Osler M, Helms Andreasen A, Heitmann B et al. (2002) Food intake patterns and risk of coronary heart disease: a prospective cohort study examining the use of traditional scoring techniques. Eur J Clin Nutr 56, 568-574.

30. Terry P, Hu FB, Hansen H et al. (2001) Prospective study of major dietary patterns and colorectal cancer risk in women. Am J Epidemiol 154, 1143-1149.

31. Costacou T, Bamia C, Ferrari P et al. (2003) Tracing the Mediterranean diet through principal components and cluster analyses in the Greek population. Eur J Clin Nutr 57, 1378-1385.

32. Sánchez-Villegas A, Delgado-Rodríguez M, Martínez-González MA et al. (2003) Gender, age, socio-demographic and lifestyle factors associated with major dietary patterns in the Spanish Project SUN (Seguimiento Universidad de Navarra). Eur J Clin Nutr 57, 285-292.

33. Sichieri R (2002) Dietary patterns and their associations with obesity in the Brazilian city of Rio de Janeiro. Obes Res 10, $42-48$.

34. Handa K \& Kreiger N (2002) Diet patterns and the risk of renal cell carcinoma. Public Health Nutr 5, 757-767.

35. Speck BJ, Bradley CB, Harrell JS et al. (2001) A food frequency questionnaire for youth: psychometric analysis and summary of eating habits in adolescents. J Adolesc Health 28, 16-25.

36. Balder HF, Virtanen M, Brants HA et al. (2003) Common and country-specific dietary patterns in four European cohort studies. J Nutr 133, 4246-4251.

37. Togo P, Heitmann BL, Sørensen TI et al. (2003) Consistency of food intake factors by different dietary assessment methods and population groups. BrJ Nutr 90, 667-678.

38. Gerdes LU, Brønnum-Hansen H, Osler M et al. (2002) Trends in lifestyle coronary risk factors in the Danish MONICA population 1982-1992. Public Health 116, 81-88.

39. Schulze MB, Hoffmann K, Kroke A et al. (2001) Dietary patterns and their association with food and nutrient intake in the European Prospective Investigation into Cancer and Nutrition (EPIC)-Potsdam study. Br J Nutr 85, 363-373.

40. Fung TT, Willett WC, Stampfer MJ et al. (2001) Dietary patterns and the risk of coronary heart disease in women. Arch Intern Med 161, 1857-1862.

41. Mozaffarian D, Hao T, Rimm EB et al. (2011) Changes in diet and lifestyle and long-term weight gain in women and men. N Engl J Med 364, 2392-2404.
42. He K, Hu FB, Colditz GA et al. (2004) Changes in intake of fruits and vegetables in relation to risk of obesity and weight gain among middle-aged women. Int J Obes Relat Metab Disord 28, 1569-1574.

43. Rosell M, Appleby P, Spencer E et al. (2006) Weight gain over 5 years in 21,966 meat-eating, fish-eating, vegetarian, and vegan men and women in EPIC-Oxford. Int $J$ Obes (Lond) 30, 1389-1396.

44. Masaki M, Sugimori H, Nakamura K et al. (2003) Dietary patterns and stomach cancer among middle-aged male workers in Tokyo. Asian Pac J Cancer Prev 4, 61-66.

45. Ogura M, Yamamoto T, Morita M et al. (2001) A casecontrol study on food intake of patients with recurrent aphthous stomatitis. Oral Surg Oral Med Oral Pathol Oral Radiol Endod 91, 45-49.

46. Chen H, Ward MH, Graubard BI et al. (2002) Dietary patterns and adenocarcinoma of the esophagus and distal stomach. Am J Clin Nutr 75, 137-144.

47. Maskarinec G, Novotny R \& Tasaki K (2000) Dietary patterns are associated with body mass index in multiethnic women. J Nutr 130, 3068-3072.

48. Hu FB (2005) Protein, body weight, and cardiovascular health. Am J Clin Nutr 82, 1 Suppl., 242S-247S.

49. Ganganna P \& Johnson AA (1985) A new nutrient index for measuring nutritional well-being of Indian states. Int J Vitam Nutr Res 55, 315-322.

50. Ganguli D, Das N, Saha I et al. (2011) Major dietary patterns and their associations with cardiovascular risk factors among women in West Bengal, India. Br J Nutr 105, 1520-1529.

51. Daniel CR, Prabhakaran D, Kapur K et al. (2011) A crosssectional investigation of regional patterns of diet and cardio-metabolic risk in India. Nutr J 10, 12.

52. Togo P, Osler M, Sørensen TI et al. (2001) Food intake patterns and body mass index in observational studies. Int J Obes Relat Metab Disord 25, 1741-1751.

53. Popkin BM (1998) The nutrition transition and its health implications in lower-income countries. Public Health Nutr 1, 5-21.

54. Greenwood DC, Cade JE, Draper A et al. (2000) Seven unique food consumption patterns identified among women in the UK Women's Cohort Study. Eur J Clin Nutr 54, 314-320.

55. Ruby MB (2012) Vegetarianism. A blossoming field of study. Appetite 58, 141-150. 